\title{
O trabalho do Cirurgião-Dentista na Atenção Primária à Saúde: entre o prescrito e o real
}

\author{
The work of the dental surgeon in Primary Health Care: between the \\ prescribed and the real
}

Wagner Gomes Reis', Magda Duarte dos Anjos Scherer ${ }^{\mathbf{2}}$, Daniela Lemos Carcereri ${ }^{\mathbf{3}}$

RESUMO No cenário mundial, o Cirurgião-Dentista atua, sobretudo, no setor privado. No Brasil, esta realidade começa a mudar com a inclusão desse profissional na Estratégia Saúde da Família (ESF). Este estudo de caso realizado no Centro-Oeste do Brasil busca compreender o trabalho do dentista nesse contexto, através de análise documental, observação do trabalho e entrevistas. Da análise temática de conteúdo emergiram duas categorias: condições para o trabalho na ESF e modo de trabalho na ESF. A influência histórica do modelo de atenção individual, o contexto adverso do trabalho, as concepções de ESF dos profissionais e a autonomia que lhes é conferida restringem sua atuação.

PALAVRAS-CHAVE Saúde bucal; Atenção Primária à Saúde; Odontólogos.

ABSTRACT On the world scene, the dental surgeon acts, mostly, in the private sector. In Brazil this reality begins to change with the inclusion of this professional in the Family Health Strategy (ESF). This case study performed in the central-western of Brazil seeks to comprehend the dentist's work within this context, through documental analysis, observation of work and interviews. From the thematic overview of content emerged two categories: the working conditions and the way of working at the ESF. The historical influence of the individual care model, the adverse context of work, the conceptions that professionals have about ESF and the autonomy which is granted to them constrain their performance.

KEYWORDS Oral health; Primary Health Care; Dentists.

1Secretaria de Saúde do Distrito Federal - Brasília (DF), Brasil.

wgreis@globo.com

2 Universidade de Brasília (UnB), Departamento de Saúde Coletiva - Brasília (DF), Brasil.

magscherer@hotmail.com

3 Universidade Federal de Santa Catarina (UFSC),

Departamento de

Odontologia - Florianópolis

(SC), Brasil.

daniela_carcereri@hotmail.

com 


\section{Introdução}

O modelo brasileiro de atenção à saúde caracteriza-se pela conjugação de ações e serviços de promoção, proteção e recuperação da saúde, sendo organizado de forma regionalizada e hierarquizada. Sua principal porta de entrada é a Atenção Primária à Saúde (APS), que deve ser a ordenadora da rede de atenção, preferencialmente por meio da Estratégia Saúde da Família (ESF).

A ESF vem demonstrando potência para reorganizar a prática na APS. Constitui-se em inovação tecnológica na gestão e na organização do trabalho, e reúne diretrizes de vanguarda (MATTOS ET AL., 2014). É operacionalizada mediante a implantação de equipes multiprofissionais em Unidades Básicas de Saúde (UBS), responsáveis pelo acompanhamento de número definido de famílias localizadas em área geográfica delimitada.

No cenário mundial, o Cirurgião-Dentista (CD) atua predominantemente no setor privado. No Brasil, a inserção desse profissional no serviço público foi reforçada desde o ano 2000, com as chamadas Equipes de Saúde Bucal (EqSB) na ESF (BRASIL, 2011). Essa estratégia, associada às novas Diretrizes Curriculares Nacionais (DCN) dos cursos de graduação na área de saúde, às diretrizes para a Política Nacional de Saúde Bucal (PNSB) e à Política Nacional de Atenção Básica (PNAB) contribuem para o deslocamento do campo técnico da odontologia para o campo da Saúde Bucal Coletiva (SBC) (BOTAZZO; CHAVES, 2013).

A literatura registra diversos estudos que analisam a atenção à saúde bucal na ESF (PAIM; SOARES, 2011; PEREIRA ET AL., 2012). Todos destacam seu caráter inovador e registram as dificuldades e os avanços obtidos, entretanto, nenhum buscou compreender mais especificamente o trabalho do CD na ESF: Como o CD desenvolve seu trabalho? De que maneira enfrenta as inúmeras prescrições surgidas no processo de mudança ainda recente do modelo assistencial?
Para atuar na ESF o CD precisa desenvolver competências para além do seu 'núcleo do saber', saindo do isolamento da prática restrita ao consultório e ao equipamento odontológico, assumindo um novo papel na equipe e nas ações de promoção à saúde. $\mathrm{E}$ isto se constitui em um desafio, na medida em que se faz necessário integrar a prática dos profissionais diante de um cenário marcado pela maneira fragmentada com que cada especialidade ou subespecialidade cuida de apenas uma parte da atividade (SCHERER; PIRES; SCHWARTZ, 2009).

Toda atividade profissional apresenta um aspecto que envolve sua prescrição, ou seja, um conjunto de antecipações e outro que se vincula à realização da atividade concreta de trabalho. São três as dimensões, chamadas por Schwartz (1998A) de ingredientes da competência, que buscam predefinir a atividade de trabalho: a heterodeterminação, com as prescrições e os recursos tecnológicos disponíveis para a atividade; as experiências apreendidas no trabalho, que, formando um conjunto de valores científicos e culturais do coletivo, guiam e influenciam na atividade; e a dimensão dos valores.

A formação acadêmica, as políticas públicas e as atribuições profissionais constituem as principais normas antecedentes do CD, que antecipam a atividade antes de começar a agir. E o agir é um entrecruzamento de normas antecedentes e de tentativas de renormalização, na relação com o meio de vida, onde ocorre um debate permanente de valores que resultam em escolhas feitas por indivíduos e grupos, dada a insuficiência das prescrições para tornar o trabalho eficaz. "As renormalizações são as múltiplas gestões de variabilidades, a transgressão de normas, assim como a construção de redes e de comunicação que o trabalho requer" (SCHERER; PIRES; JEAN, 2013, P. 3205).

Como normas antecedentes para o trabalho na APS destacam-se ainda as ordens da hierarquia institucional, os procedimentos, as normas técnicas, as diretrizes (BRASIL, 2008, 
2011) e os objetivos transmitidos aos trabalhadores relativos aos prazos e à produtividade.

Considera-se que a atividade profissional exige a presença de normas, que devem ser identificadas e analisadas para se compreender um trabalho, mas que também é fundamental 'enxergar' a dinâmica das renormalizações e da singularidade da prática do trabalho profissional, nem sempre visíveis.

Mesmo quando os profissionais buscam colocar em prática os protocolos, sempre há um encontro de diferentes vontades, sujeitos e necessidades, onde diferentes negociações de eficácia são realizadas (RAMMINGER; BRITO, 2011). Isso vai determinar, por exemplo, se um CD fará uma palestra de orientação de higiene oral a um grupo de usuários ou se, além disso, irá dialogar com cada um deles sobre a técnica de escovação, ou, ainda, se irá pegar na mão e na escova de um deles, ensinando a todos sobre a maneira correta de realizar os movimentos. Isso denota a complexidade da atividade do trabalho em saúde. Somam-se a isso os constrangimentos do meio, que podem alterar ou impedir a realização de atividades.

O trabalho na ESF fomenta mudanças na atuação do CD pela chamada 'intercessão partilhada', ou seja, a relação existente não só entre o profissional e o paciente, mas o envolvimento de um contexto amplo, que vai desde o serviço até a família e a comunidade. Atitudes como o vínculo e o acolhimento tomam uma dimensão maior na ESF (SANTOS ET AL., 2008) e vão exigir o desenvolvimento de novas competências.

Para que o trabalho de saúde bucal na ESF integre toda a equipe de profissionais, buscando o conhecimento integral e a construção coletiva das intervenções, e não apenas articulações pontuais e encaminhamentos internos, é essencial que todos compreendam, em toda a sua complexidade, o processo saúde-doença, e ampliem a intervenção sobre determinado problema, outrora reservado à atividade do CD (FACCIN; SEBOLD; CARCERERI, 2010).
Nesse sentido, a gerência dos serviços precisa superar a influência do modelo taylorista de administração, que regula o trabalhador apenas na conduta do prescrito por ela, e que, com isso, limita as renormalizações necessárias para a produção de eficácia no trabalho. $\mathrm{O}$ fato de o trabalho real diferir do prescrito constitui um dos elementos essenciais para a compreensão de como o trabalho se desenvolve na realidade.

Após mais de dez anos da inserção da saúde bucal na ESF, ainda são poucos os estudos que abordam o trabalho do CD nesse contexto (BOTAZZO; CHAVES, 2013). No Brasil, o Distrito Federal (DF) foi um dos pioneiros na inclusão de EqSB no Programa Saúde da Família (PSF) (ZANETTI, 2001), sendo, pelo seu histórico, cenário propício. Estudos desta natureza podem contribuir para reorientar prescrições e a gestão do trabalho. Este artigo tem como objetivo compreender o processo de trabalho do CD na ESF, tendo como referência a ergologia e as prescrições para a APS.

\section{Percurso metodológico}

Trata-se de estudo de caso (YIN, 2005), com abordagem qualitativa e triangulação na coleta e na análise de dados (MINAYO, 2004). A unidade de análise é o trabalho do CD. Os seis CDs participantes, vinculados a três UBS de três regionais de saúde, foram incluídos a partir de indicação dos gestores, obedecendo a critérios qualitativos: serem CDs integrantes de equipes completas e afinadas com as prescrições da ESF; e serem CDs com reconhecida identidade e atuação conforme princípios e diretrizes da ESF. Eram mulheres com idades entre 30 e 55 anos, que trabalhavam na APS por um período que variou entre 1 e 13 anos, sendo de 1 a 7 anos na ESF. Destas, quatro tinham atualização ou especialização em saúde da família ou saúde coletiva.

Os dados foram coletados no período de fevereiro de 2012 a março de 2013, através de análise documental, observação das 
situações de trabalho dos CDs e entrevistas semiestruturadas.

Foram analisados registros diários de atividades, relatórios, atas de reunião e planos de ação elaborados pela equipe da ESF e pelos CDs. As observações em turnos de quatro horas totalizaram de 12 a 16 horas por UBS. Buscou-se identificar as atividades desenvolvidas pelos profissionais, como são realizadas e o que interfere na sua implementação, a inserção do CD na equipe, a relação com os usuários e as condições de trabalho. A coleta foi guiada por roteiro baseado nas prescrições para o trabalho da PNAB e do referencial da ergologia, considerando que a atividade de trabalho é como as pessoas se engajam na gestão dos objetivos do trabalho, servindo-se dos meios disponíveis ou inventando outros para fazer frente às variabilidades e produzir sentido no trabalho. Tal processo é sempre o resultado de um debate de normas e valores em um confronto com o que o meio oferece e com a capacidade do profissional de agir (SCHWARTZ, 1998B).

Os dados da observação e da análise documental geraram roteiro para as entrevistas semiestruturadas e foram tratados pela análise temática de conteúdo (MINAYO, 2004), que inclui a leitura das evidências produzidas, a codificação das unidades de significado e a elaboração das categorias temáticas. Desse processo emergiram duas categorias temáticas: condições para o trabalho na ESF e o modo de trabalhar na ESF. O projeto foi aprovado no Comitê de Ética em Pesquisa da Secretaria de Estado de Saúde do DF, sob o $n^{\circ} 240 / 2012$.

\section{Resultados e discussão}

\section{Condições para o trabalho na ESF}

As informações colhidas evidenciaram limitações na disponibilidade de insumos e instrumentos, na infraestrutura das instalações e também na gestão e organização do trabalho.
Houve consenso sobre a falta de treinamento e preparo para o trabalho na APS. Os profissionais, identificados apenas pelas iniciais de seus nomes, relataram os desafios enfrentados no processo de busca pelos conhecimentos: "[...] fui falando com os colegas, eles foram me explicando mais ou menos como funcionava. Eu não tive treinamento algum, nem apresentada formalmente eu fui. Tive que ir buscando as coisas" (ADB). "Nenhum, fui jogada!” (ELB). "[...] eu não tive nenhuma formação, nenhuma orientação. Simplesmente, nós fomos colocados nesse local e nos entregaram o Caderno 17, e falaram: 'Bom, aqui é para ser executada a Atenção Básica” (MLC).

A falta do domínio das normas antecedentes, considerado por Schwartz (1998A) como o primeiro ingrediente da competência, neste caso, de como operar a saúde bucal na ESF, confere limites à atuação do $\mathrm{CD}$, que vai adquirindo esses saberes aos poucos, na medida em que, por si só, vai se apropriando da natureza do serviço. Por outro lado, à medida que o profissional vai buscar, por conta própria e ao longo do tempo, o conhecimento pertinente ao seu trabalho, incorporando pouco a pouco histórico e saberes, através da experiência que constrói, ele está desenvolvendo o segundo ingrediente da competência, que trata da dimensão experimental do trabalho.

Estudos demonstram que o trabalho realizado nunca corresponde exatamente àquele fixado pelas regras ou mesmo por objetivos predeterminados. Assim, mesmo em situações em que as regras são socializadas, a variabilidade no momento da execução da tarefa é enorme e até mesmo imprevisível. O trabalho apresenta-se sempre revestido de complexidade e, por envolver a atividade humana, nunca se resume à prescrição, ao contrário da lógica taylorista, que defende que seguir as normas e protocolos seria suficiente.

Embora a análise documental tenha evidenciado a existência de referenciais formais a serem seguidos, quanto ao planejamento e à estruturação do trabalho, a prática revelou autonomia dos CDs para gestão: 
[...] eu crio a minha rotina. A gente precisa atender determinadas faixas etárias, tem uma porcentagem que a gente tem que atender. Mas não é especificado quantas vezes a gente tem que fazer a palestra, com quem a gente faz. Então a gente cria essa rotina. (ADA).

"Aqui, se você quiser, você consegue realizar um bom trabalho" (ELB).

Essa liberdade que o CD desfruta em seu trabalho no DF, por um lado, favorece o poder criativo do profissional, diante das exigências das situações reais do trabalho. Por outro lado, o estudo sugere que o movimento de inovar no trabalho está diretamente relacionado ao 'querer fazer', ou seja, ao comprometimento do profissional com a finalidade de seu trabalho, bem como ao 'poder agir', ingredientes da competência que resultam do debate de valores e das escolhas dos profissionais, bem como da capacidade de enfrentar os constrangimentos do meio. Neste sentido, para que o trabalho do CD seja resolutivo, é preciso haver sempre combinações de graus de autonomia com responsabilidade no desenvolvimento de suas ações.

A falta de diálogo do gestor com as Equipes de Saúde Bucal, antes do início das atividades, e a falta de capacitação e perfil para o trabalho, aliadas à autonomia existente, podem gerar diferenças no que se refere às atividades desenvolvidas, como pode ser verificado pelos seguintes relatos:

Mas uma coisa a gente prioriza: é a parte do trabalho educativo e preventivo [...]. Então, quando a gente vai iniciar o tratamento de um paciente, ele só inicia o atendimento na cadeira após passar por uma palestra educativa e preventiva, com ilustração de vídeos. (MLC).

“Noventa por cento curativa [...]” (SUB). A pesquisa levanta a questão-chave de que, em tese, todos estão em condições de trabalhar à luz do modelo, porém, as dificuldades encontradas informam uma dura realidade.
Condição de trabalho 'ideal' exige investimento dos gestores junto aos trabalhadores, no sentido de qualificá-los para o desafio da ESF. Além disso, é necessário proporcionar estabilidade e segurança funcional para que desempenhem suas atividades com motivação, compromisso e tranquilidade. Este é um dos pontos fortes da realidade estudada, pois todos os CDs do DF estão inseridos no regime estatutário e gozam de um plano de carreira específico. Tal fato pode também contribuir para o exercício pleno da liberdade que lhes é conferida para a gestão do próprio trabalho.

\section{O modo de trabalho na ESF}

O modo de trabalho é influenciado pelo interesse e pela afinidade do profissional com o seu trabalho. Houve um consenso de que a filosofia de trabalho da ESF seria importante para os usuários e para a sociedade, porém as entrevistas denotaram contrastes, tais como:

Eu gosto de lidar com comunidades, acho que atender uma família fica mais fácil de abordar. Gosto de trabalhar em equipe, ter outros profissionais junto (ADA). Eu sempre me identifiquei com esse tipo de trabalho. Eu observava que os atendimentos que não fazem parte do Programa Saúde da Família eram aquela coisa meio que olhando só o problema, a doença, não davam foco à pessoa [...]. (MLC).

E, por outro lado: "Foi uma razão pessoal, eu precisava das 40 horas. E, na época, a gerente disse que a única maneira de eu conseguir seria vindo para cá, porque ninguém queria vir" (ELB). "Com nada, eu não me identifico com nada. Nem com o trabalho e nem com o grupo" (SUB).

Os relatos acima mostram uma dicotomia de perfis para o trabalho na ESF. A intercessão partilhada (SANTOS ET AL., 2008) exigida na ESF fica comprometida em decorrência da 
dificuldade do trabalhador de se identificar com essa nova proposta, na qual o relacionamento profissional com o usuário assume novas dimensões (MERHY; FRANCO, 2003).

Essa diferença de prazeres na prática profissional interfere na maneira com que os profissionais lidam com os protocolos e também com as renormalizações produzidas diariamente no trabalho. Essas renormalizações podem ser, por exemplo, construídas com o intuito de melhorar o resultado final da atividade, mas também para reduzir ou desconstruir determinada tarefa.

A satisfação pessoal, o gosto por trabalhar com comunidades e em equipe, o foco na saúde e não na doença são observáveis na maioria dos relatos e, de maneira geral, não ficou evidenciado, nas observações e nas entrevistas, que os profissionais exerceram seus trabalhos em condições de insatisfação.

Observou-se uma predominância de atividades curativas e preventivas individuais, em detrimento de ações de promoção de saúde coletivas. Em ocorrência menor, foram realizadas ações de promoção à saúde com grupos previamente selecionados para o atendimento clínico, tais como orientações sobre higiene bucal e escovação supervisionada, com distribuição de escovas de dente e creme dental; e orientações sobre o funcionamento do serviço de odontologia e também sobre a programação do tratamento, sendo que o trabalho era desenvolvido preferencialmente no contexto da UBS. A pesquisa revela a hegemonia do modelo de atenção centrado no fazer odontológico. Botazzo e Chaves (2013), ao discutirem os antecedentes e o estado da arte da SBC, no Brasil, registram que os limites das suas práticas fazem parte de um processo histórico em superação.

O modo como se trabalha está ligado também a uma visão de mundo, seja ela particular ou partilhada por um coletivo:

Na minha opinião, sair do centro de saúde para ir 'na' casa de uma pessoa, que, muitas vezes, não tem uma boa iluminação... A pessoa, às vezes, nem está querendo te receber naquela hora... Eu considero que tirar o profissional do centro de saúde, que poderia estar fazendo vários atendimentos... Ele está andando, às vezes, em áreas perigosas, [...] inclusive, eu acho que isso leva as pessoas a ficarem muito acomodadas. (ADB).

Uma das coisas que dificultam o nosso trabalho é a questão cultural da localidade, porque as pessoas não ouvem muito a parte preventiva, [...] eles só querem saber do curativo. E quando é palestra, eles falam: 'Aí, mas que saco, eu tenho que fazer isso!'. (ELB).

Há, nitidamente, um conflito entre o protocolo da ESF e aquilo que os CDs valorizam e julgam viável e pertinente que seja feito. Os depoimentos revelam medo da violência, maior valorização do trabalho dentro da UBS e pouco vínculo com os usuários dos serviços. Sendo assim, o profissional contorna ou modifica as prescrições, mantendo-se no modelo tradicional de atenção à demanda espontânea e de cuidado individual.

As renormalizações no trabalho se dão quando o profissional 'enxerga' a necessidade de alterar uma prescrição prévia em busca do seu objetivo de alcançar o resultado, orientado pelas escolhas que ele mesmo faz, em função de um debate de valores. As normas operatórias não são separadas das normas da individualidade. Nisso, ocorre a todo tempo o confronto entre as normas antecedentes e as tentativas de renormalizações pelo trabalhador (SCHWARTZ, 2011).

A lógica taylorista defende que seguir as normas e os protocolos seria suficiente para a realização do trabalho. Ao se deparar com a tarefa, o trabalhador se vê diante de imprevistos, muitas vezes impossíveis de se determinar e equacionar com precisão prévia.

Observou-se a preocupação do profissional com a necessidade de encontrar alternativas para o enfrentamento de problemas diários: 
[...] a autoclave quebrou, a gente juntava os instrumentais; a TSB fazia um embrulho, colocava o nome e eu levava no centro de saúde para esterilizar. À tarde, no outro dia, passava lá, pegava e trazia [...] o exame é enviado para o centro de saúde, só que não vem para cá. Aí, o que acontece: eu tenho que ir buscar quase toda semana [...] as radiografias. (ADA).

O estudo evidencia as renormalizações produzidas pelo CD em sua rotina de trabalho, visando agilizar e ser eficiente, realizando tarefas que seriam de responsabilidade da área administrativa. Nesse caso, a renormalização ocorreu para minimizar um dano e para que o trabalho pudesse ser concluído. $\mathrm{O}$ meio, sempre infiel (SCHWARTZ, 1998B), interfere no trabalho do profissional em proporções variadas, a cada dia, nunca sendo o mesmo.

$\mathrm{O}$ 'modo de trabalho' prescrito para o CD na ESF e na APS (BRASIL, 2008, 2011), se difere do trabalho curativo individualizado tradicional. As ações de atenção integral, extrapolando os limites da boca, bem como a participação no processo de territorialização e planejamento da atuação da equipe, são exemplos das ações nas quais o CD deve estar integrado, com os diferentes profissionais. A pesquisa demonstra que há, ainda, um longo percurso para a efetivação da saúde bucal no DF, segundo as diretrizes estabelecidas. "A gente não se atém ao Caderno 17, mas todos nós já tivemos essa orientação, e acho que, no fundo, a gente segue um pouco, né?" (ELB). "[...] eu sigo muita coisa lá, que 'estão' no Caderno 17, mas eu tenho liberdade para outras coisas" (ADB). "Conheço. A gente tenta trabalhar 'em cima' do Caderno. Só que a gente tenta adequar à nossa realidade, porque não tem jeito de seguir exatamente como é" (CLC).

Percebe-se que a execução dos protocolos (BRASIL, 2008; 2011) na prática de trabalho do CD sofre variações. Há a compreensão, pelos profissionais, de que esses protocolos não são suficientes para atender às necessidades reais do profissional, e de que, no momento da execução, cada um reinventa-o à sua maneira, com seus valores e sua história, preenchendo as lacunas da prescrição e, assim, atendendo às exigências do processo produtivo.

Destaca-se que o agir profissional é influenciado pelas características intrínsecas de cada ser humano, mas sempre em uma relação dialética com o meio. Sem essa compreensão, corremos o risco de reduzir os entraves à implementação e à integração da saúde bucal na ESF à culpabilização dos indivíduos e grupos, como se a capacidade deles de operar as diretrizes da APS não fizessem parte de um contexto macro (sistema de saúde), meso (nível da gestão) e micro (do cotidiano dos serviços).

A organização do modelo de saúde geral existente no lócus de desenvolvimento da ação, a UBS, prevalece como indutora da organização das ações de saúde bucal (BULGARELLI ET AL., 2014), e, no caso do DF, novos estudos devem considerar a cobertura atual e a história de implantação da ESF ao se analisar o trabalho dos CDs.

\section{Considerações finais}

A pesquisa mostra que o contexto e o modo de trabalho dos CDs do DF dificultam que os profissionais exerçam os princípios da APS, tais como a coordenação do cuidado, a longitudinalidade e a integralidade, bem como a orientação familiar e comunitária.

Ter liberdade para introduzir mudanças necessárias à realidade de cada território é fundamental na lógica do modelo, mas é preciso que o processo de trabalho aconteça respeitando as necessidades de saúde da população.

Os achados da pesquisa indicam um grande caminho a percorrer pelo CD para se aproximar do que está prescrito pelas diretrizes nacionais. O CD ainda é um profissional solitário na UBS; mesmo na ESF, o processo de trabalho ainda permanece 
centrado nele. Neste sentido, o trabalho em equipe não é fortalecido e restringe a efetividade das ações de promoção da saúde. A influência histórica do modelo de atenção individual, o contexto adverso do trabalho, as concepções de ESF dos profissionais e a autonomia que lhes é conferida restringem sua atuação como CD da ESF.

\section{Referências}

BOTAZZO, C.; CHAVES, S. C. L. Saúde Bucal Coletiva: Antecedentes e estado da arte. In: BOTAZZO, C. Diálogos sobre a boca. São Paulo: Hucitec; 2013.

BRASIL. Ministério da Saúde. Departamento de Atenção Básica. Portaria $n^{\circ}$ 2.488, de 21 de outubro de 2011. Aprova a Política Nacional de Atenção Básica, estabelecendo a revisão de diretrizes e normas para a organização da Atenção Básica, para a Estratégia Saúde da Família (ESF) e o Programa de Agentes Comunitários de Saúde (PACS). 2011. Disponível em: $<$ http://www.saude.mt.gov.br/upload/legislacao/2488 [5046-041111-SES-MT].pdf >. Acesso em: 17 set. 2012.

. Ministério da Saúde. Secretaria de Atenção à Saúde. Departamento de Atenção Básica. Saúde bucal. Brasília: Ministério da Saúde, 2008. 92 p. (Cadernos de Atenção Básica; 17) (Série A. Normas e Manuais Técnicos)

BULGARELI, J. et al. A resolutividade em saúde bucal na atenção básica como instrumento para avaliação dos modelos de atenção. Ciênc. saúde coletiva, Rio de Janeiro, v. 19, n. 2, p. 383-391, 2014.

DISTRITO FEDERAL. Secretaria de Estado de Saúde. Subsecretaria de Atenção Primária à Saúde. Diretoria de Gestão da Atenção Primária. Gerência de Monitoramento e Avaliação. Relatório final de equipes e cobertura da ESF. Brasília: Secretaria de Estado de Saúde, 2013.

FACCIN, D.; SEBOLD, R.; CARCERERI, D. L. Processo de trabalho em saúde bucal: em busca de diferentes olhares para compreender e transformar a realidade. Ciênc. saúde coletiva, Rio de Janeiro, v. 15, n. supl. 1, p. $1643-1652,2010$

MATTOS, G. C. M. et al. A inclusão da Equipe de Saúde Bucal na Estratégia Saúde da Família: entraves, avanços e desafios. Ciênc. saúde coletiva, Rio de Janeiro, v. 19, n. 2, p. 373-378, 2014.

MERHY, E. E.; FRANCO, T. B. Por uma composição técnica do trabalho centrada nas tecnologias leves e no campo relacional. Saúde debate, Rio de Janeiro, v. 27, n. 65, p. 316-323, 2003.

MINAYO, M. C. S. O desafio do conhecimento: pesquisa qualitativa em saúde. 8. ed. São Paulo: Hucitec; Rio de Janeiro: Abrasco; 2004.

PAIM, J. S.; SOARES, C. L. M. Aspectos críticos para a implementação da política de saúde bucal no município de Salvador, Bahia, Brasil. Cad. Saúde Pública, Rio de Janeiro, v. 27, n. 5, p. 966-974, 2011.

PEREIRA, C. R. S. et al. Impacto da Estratégia Saúde da Família sobre indicadores de saúde bucal: análise em municípios do Nordeste brasileiro com mais de $100 \mathrm{mil}$ habitantes. Cad. Saúde Pública, Rio de Janeiro, v. 28, n. 3, p. 449-462, 2012.

RAMMINGER, T.; BRITO, J. C. "Cada Caps é um Caps": Uma coanálise dos recursos, meios e normas presentes nas atividades dos trabalhadores de saúde mental. Psicol. Soc., Florianópolis, v. 23, n. esp., p. 150160, 2011. 
SANTOS, A. M. et al. Vínculo e autonomia na prática de saúde bucal no Programa Saúde da Família. Rev. Saúde Pública, São Paulo, v. 42, n. 3, p. 464-470, 2008.

SCHERER, M. D. A.; PIRES, D.; SCHWARTZ, Y.

Trabalho coletivo: um desafio para a gestão em saúde.

Rev. Saúde Pública, São Paulo, v. 43, n. 4, p. 721-725, 2009.

SCHERER, M. D. A.; PIRES, D. E. P.; JEAN, R. A construção da interdisciplinaridade no trabalho da Equipe de Saúde da Família. Ciênc. saúde coletiva, Rio de Janeiro, v. 18, n. 11, p. 3203-3212, 2013.

SCHWARTZ, Y. Os ingredientes da competência: um exercício necessário para uma questão insolúvel. Educ. Soc., Campinas, v. 19, n. 65, p. 101-139, 1998a.

SCHWARTZ, Y. Reconnaissances du travail: pour une approche ergologique. 2. ed. Paris: PUF; 1998b.
SCHWARTZ, Y. Conceituando o trabalho, o visível e o invisível. Trab. educ. saúde, Rio de Janeiro, v. 9, n. supl. 1, p. 19-45, 2011.

YIN, R. K. Estudo de caso: planejamento e métodos. Porto Alegre: Bookman; 2005.

ZANETTI, C. H. G. O apoio do Ministério da Saúde para inclusão da saúde bucal. 2011. Disponível em: <http://164.41.147.200/ecm/biblioteca/ ZANETTI_2001_OPINIAO_psf\&sb_ms.pdf $>$ Acesso em: 11 mar. 2013.

Recebido para publicação em abril de 2014 Versão final em agosto de 2014 Conflito de interesses: inexistente

Suporte financeiro: não houve 